\title{
Evaluation of hygiene and food handling attitudes and practices during social isolation due to COVID-19 in Peruvian households: a cross-sectional study
}

\author{
Cahuana Díaz, E.B., Revoredo Torres, I.G. and *Saintila, J. \\ Department of Nutrition, School of Human Nutrition, Faculty of Health Sciences, Universidad Peruana \\ Unión, Lima, Peru.
}

\author{
Article history: \\ Received: 27 November 2020 \\ Received in revised form: 10 \\ January 2020 \\ Accepted: 8 March 2021 \\ Available Online: 27 June \\ 2021
}

Keywords:

Attitudes,

Practices,

Food Safety,

COVID-19,

Peru

DOI:

https://doi.org/10.26656/fr.2017.5(3).685

\begin{abstract}
The pandemic has affected almost all areas of people's lives and the way food is prepared is no exception. Food safety has been hit the hardest in the COVID-19 era. The aim of this paper was to investigate the attitudes and hygienic practices and food handling during social isolation by COVID-19 in Peruvian homes. A cross-sectional study was conducted that included 538 participants over 18 years of age from all regions of Peru, administering an online survey of 15 questions. The sample was selected by nonprobability sampling for convenience. The data were analysed using the statistical software IBM SPSS version 24 and the Chi-square test was used. A significance level of 5\% was considered. Women represented the highest percentage of the sample (73.0\%). $87.7 \%$ of the participants considered correct handling of food at home important during social isolation. Whereas $49.7 \%$ of the sample reported that they began to emphasize good handling practices when the COVID-19 pandemic began. Hand washing practices were more frequent in participants with a higher level of education $(p<0.001)$. In general, the participants demonstrated a positive attitude and were aware of the role of hygienic practices when handling food.
\end{abstract}

\section{Introduction}

In January 2020, WHO officially declared COVID19 a global health emergency, representing a serious risk to the health and survival of populations (Phelan et al., 2020; Velavan and Meyer, 2020). In Peru, the first case of contagion was reported by the state on March 6, 2020. To mitigate the transmission of the disease, the Peruvian authorities have implemented a series of preventive measures to contrast and contain the spread of the disease. On March 11 of the same year, the government, through Supreme Decree No. 008-2020-SA, declared a state of health emergency at the national level for a period of ninety calendar days, dictating prevention and control measures for COVID-19 (Gobierno del Perú, 2020a). These measures were extended until September 7 and December 31, 2020, respectively (Gobierno del Perú, 2020b).

The pandemic has affected almost all walks of life of people, and the way of preparing food is no exception. Food safety is one of the most affected aspects in the era of the COVID-19 pandemic (Galanakis, 2020). There is a possible transmission of COVID-19 through food. The coronavirus can reach fresh food products such as vegetables, fruits, or bakery products (Rizou et al., 2020). Transmission appears to be possible if the virus is transferred shortly thereafter through hands or food to the mucous membranes of the mouth, throat, or eyes (Rizou et al., 2020). Therefore, the FDA suggests personal hygiene, such as hand washing, surface disinfection, keeping clean in food preparation environments are the main measures that should be applied during food handling (FDA, 2020).

Likewise, the authorities of the Ministry of Health of Peru, to draw the attention of the population to the importance of good food handling practises at home during COVID-19, have carried out a series of sessions education on food safety, nutrition, and healthy lifestyle practices to mitigate transmission risks (Ministerio de Salud del Perú, 2020). Positive attitudes and proper hygiene practices during handling at home play a vital role in ensuring food safety and protecting family members from infection, cross-contamination, food poisoning, and the risk of COVID-19 transmission (Tegegne and Phyo, 2017). There are few studies on whether a global public health emergency, such as the COVID-19 pandemic, can affect people's attitudes and practices around food handling (Luo et al., 2020). The 
objective of this study was to investigate the attitudes and hygienic practices and food handling during social isolation by COVID-19 in Peruvian homes.

\section{Materials and methods}

\subsection{Design, type of research, and participants}

A cross-sectional study was carried out, applying an online questionnaire during October 2020. The questionnaire was sent to people who were 18 years old at all levels of satiety and from all regions of the country (coast, jungle, and mountain ranges). Social media (WhatsApp, Instagram, and Messenger) and email were used to send the questionnaire link to friends, students, colleagues, and professionals, and their referrals helped us to recruit more participants. The selection of the participants was made by nonprobability sampling for convenience (Otzen and Manterola, 2017). A total of 585 participants voluntarily decided to participate in the study. However, 47 were excluded because they reported that they do not handle food at home. The first section of the questionnaire contained an informed consent briefly describing the purpose of the study, the rights of the participants, and the confidentiality in the use of the data. Likewise, they were informed that the time to answer the survey was on average 10 to 15 mins. Furthermore, the participants could not answer the questionnaire if they did not express the "desire to participate" after reading the informed consent. Those who did not want to participate only needed to check the option "I do not wish to participate" and then go to the closing page of the questionnaire. The study was approved by the Bioethics Research Committee of the Universidad Peruana Unión and registered with the reference number: $\mathrm{N}^{\circ}$ 00126-2020/UPeU/FCS/CIISA.

\subsection{Data collection instrument}

The questionnaire used was created and validated in a previous study by the Delphi method (Shi et al., 2020). The content, structure and logic of the questionnaire were discussed by university professors and food safety experts working in the food industry. The questionnaire (Torres et al., 2018) is made up of a total of 15 questions, including sociodemographic data such as age, sex, and degree of study. Some of the responses on the importance of food handling at home, where and in what order food is purchased and stored (dairy, meat, and vegetables) were dichotomous (yes or no). In addition, the participants were asked about the management of basic hygienic practices for food handling, such as hand washing, disinfection, cross-contamination, and cold chain and if they had experienced any type of food poisoning from food prepared at home during social isolation due to COVID-19 and what measures they had taken in the face of poisoning (self-medication, medical assistance, or others). They were asked if they paid greater interest and attention to good food handling practises at home prior to the COVID-19 pandemic.

\subsection{Statistical analysis}

A descriptive analysis of the study variables was carried out using tables of absolute frequencies and percentages. In addition, statistical hypothesis testing was performed to compare proportions in the level of education of the participants. These analyses were carried out considering a significance level of 5\%. All analyses were done using IBM SPSS statistical software, version 24 (SPSS Inc., Chicago, IL, USA).

\section{Result}

A total of 538 participants voluntarily responded to the questionnaire. Table 1 shows the sociodemographic characteristics of the sample. Women in this study represented the largest proportion of the sample, compared to men $(73.0 \%$ vs. $27.0 \%)$. Regarding age, it is shown that the largest proportion $(72.5 \%, n=390)$ of the sample was made up of participants aged 18 to 30, while only $1.1 \%$ represented those participants who were older than 61 years. Regarding the level of education of the participants, $53 \%$ had a university education, while $25.3 \%$ and $21.7 \%$ had a level of basic and technical education, respectively. On the other hand, the highest percentage of the sample $(72.3 \%, \mathrm{n}=368)$ reported not having worked or studied in the area of health and/or food science. Table 2 shows the description of the sample referring to the presence of foodborne diseases during social isolation by COVID-19 and the control measures that were taken by the respondents. It was found that, of the total sample $(100 \%, \mathrm{n}=538), 16.4 \%(\mathrm{n}$ $=88$ ) reported having experienced foodborne illnesses, of which $55.6 \%(\mathrm{n}=49)$ reported having gone to the doctor, while the remaining proportion self-medicated.

In Figure 1, the descriptive analysis of the importance of correct food handling is presented. Of the total sample, $87.7 \%$ considered that good hygiene and food handling practices are important, and the remaining percentage considered them moderately important. In relation to the place of purchase of fruits, vegetables, meats, and meats derivatives, dairy and eggs, groceries, and preserves (Figure 2), the preference of place that stood out among those surveyed were markets (57.5), followed by supermarkets and Wineries in $27 \%$ and $15 \%$, respectively.

Regarding the order in which the purchases of fruits and vegetables are made (Figure 3), 66.6\% of those 
surveyed reported having made the purchase at the end or in between. In relation to the purchase of meats and derivatives, $70.3 \%$ purchase these products at the beginning or intermediate during the purchase process. $56 \%$ of those surveyed purchase dairy products and derivatives at the beginning and in the middle of the purchase.

Table 1. Sociodemographic characteristics of the participants

\begin{tabular}{lcc}
\hline Variable & $\mathrm{n}$ & $\%$ \\
\hline Sex & 393 & 73.0 \\
Female & 145 & 27.0 \\
$\quad$ Male & & \\
Age (years) & 390 & 72.5 \\
$18-30$ & 92 & 17.1 \\
$31-40$ & 34 & 6.3 \\
$41-50$ & 16 & 3.0 \\
$51-60$ & 6 & 1.1 \\
$\geq 61$ & & \\
Education level & 136 & 25.3 \\
Basic & 117 & 21.7 \\
Technique & 285 & 53.0 \\
University & 149 & 27.7 \\
Work or study in the area of health or food science & \\
Yes & 389 & 72.3 \\
No & 538 & 100.0 \\
\hline Total
\end{tabular}

Table 2. Description of the sample according to the presence of foodborne diseases during the pandemic and the measures taken

\begin{tabular}{lcc}
\hline Variable & $\mathrm{n}$ & $\%$ \\
\hline Presence of foodborne illness since COVID- & started \\
Yes & 88 & 16.4 \\
No & 450 & 83.6 \\
Total & 538 & 100.0 \\
Measures taken & & \\
Go to doctor & 49 & 55.6 \\
Self-medication & 35 & 39.7 \\
Other measure & 4 & 4.7 \\
\hline Total & 88 & 100.0 \\
\hline
\end{tabular}

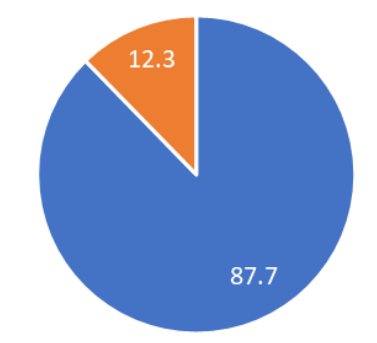

- Important - Moderately important

Figure 1. Analysis of the importance of proper food handling

When asking respondents about hygienic practices in the preparation of food at home (Figure 4), it was found that $87 \%$ defrosted food at room temperature, $97.6 \%$ washed their hands before handling food, however, $64.3 \%$ did not store food immediately after its preparation in the refrigerator. About $95 \%$ checked the expiration dates of the products while $65.1 \%$ washed the eggs and, finally, $87.2 \%$ reported using covered containers in the kitchen.

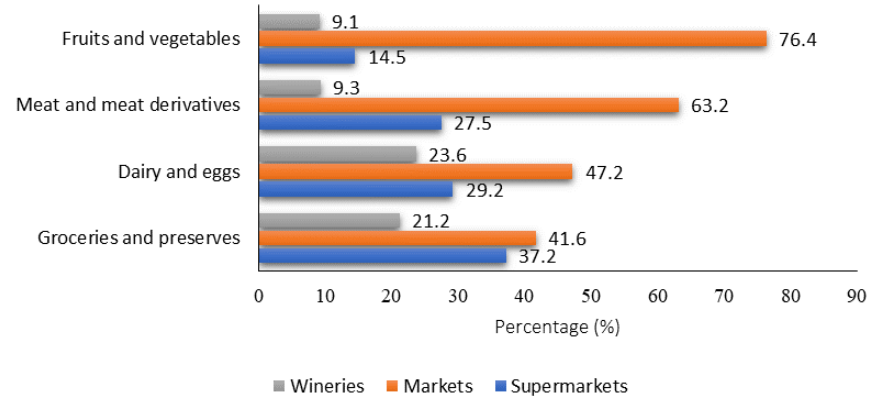

Figure 2. Place of purchase of food during the COVID-19 pandemic

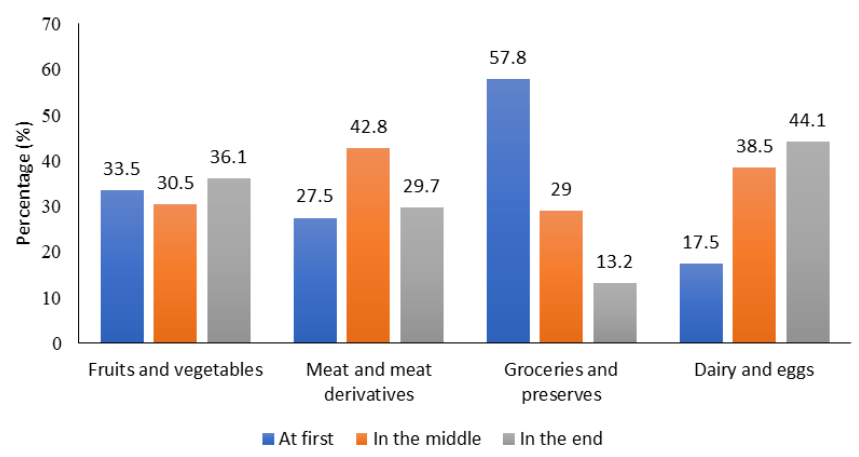

Figure 3. Order when buying food at the supermarket

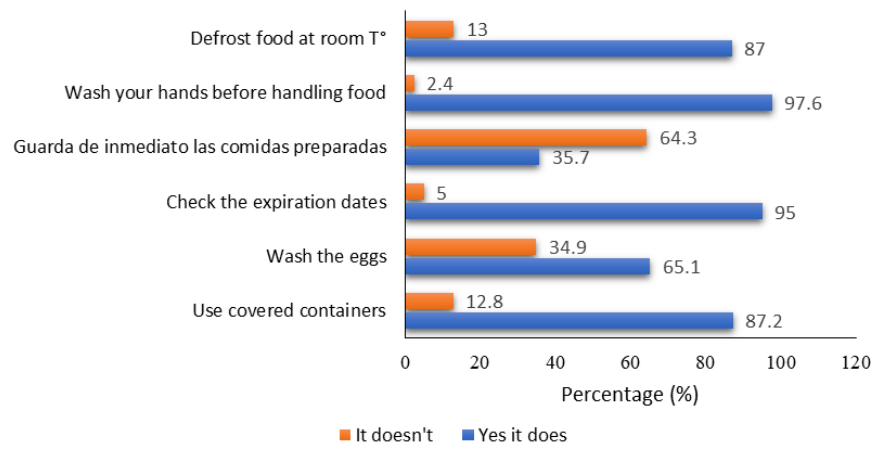

Figure 4. Good food handling practices at home

Table 3 shows the comparative analysis between hygienic attitudes and practices and food handling according to the degree of instruction of the participants. However, in general, no significant differences were observed. Except for two questions: for the question about the importance of the correct handling of food, in which respondents with higher education consider it important to handle correctly in a higher proportion $(92.3 \%)$, this difference was significant $(\mathrm{p}<0.01)$. Likewise, the question of handwashing in which the participants with the highest academic degree most frequently practised the habit of handwashing before handling food $(\mathrm{p}<0.01)$. 
Table 3. Analysis of hygienic attitudes and practices in the home according to the level of education

\begin{tabular}{|c|c|c|c|c|c|}
\hline \multicolumn{2}{|c|}{ Variable } & Basic $(\%)$ & Technique $(\%)$ & University $(\%)$ & p-value \\
\hline \multirow{3}{*}{$\begin{array}{l}\text { Importance of the correct } \\
\text { handling of food }\end{array}$} & Little & 0.0 & 0.0 & 0.0 & \multirow{3}{*}{0.001} \\
\hline & Medium & 20.6 & 13.7 & 7.7 & \\
\hline & Important & 79.4 & 86.3 & 92.3 & \\
\hline \multirow{2}{*}{$\begin{array}{l}\text { Follow an order when storing } \\
\text { food in the refrigerator }\end{array}$} & No & 25.0 & 22.2 & 19.3 & \multirow{2}{*}{0.398} \\
\hline & Yes & 75.0 & 77.8 & 80.7 & \\
\hline \multirow{2}{*}{$\begin{array}{l}\text { Emphasizes hygiene in } \\
\text { handling }\end{array}$} & Since before the pandemic & 48.1 & 52.6 & 50.0 & \multirow{2}{*}{0.816} \\
\hline & when the pandemic started & 51.9 & 47.4 & 50.0 & \\
\hline \multirow{2}{*}{ Use cutting boards } & Yes & 67.6 & 60.7 & 62.8 & \multirow{2}{*}{0.480} \\
\hline & No & 32.4 & 39.3 & 37.2 & \\
\hline \multirow{2}{*}{ Use covered containers } & Yes & 83.1 & 87.2 & 89.1 & \multirow{2}{*}{0.223} \\
\hline & No & 16.9 & 12.8 & 10.9 & \\
\hline \multirow{2}{*}{ Wash the eggs } & Yes & 65.4 & 60.7 & 66.7 & \multirow{2}{*}{0.517} \\
\hline & No & 34.6 & 39.3 & 33.3 & \\
\hline \multirow{2}{*}{ Check the expiration dates } & Yes & 92.6 & 94.0 & 96.5 & \multirow{2}{*}{0.207} \\
\hline & No & 7.4 & 6.0 & 3.5 & \\
\hline \multirow{2}{*}{$\begin{array}{l}\text { Store prepared food in the } \\
\text { refrigerator }\end{array}$} & Yes & 35.3 & 31.6 & 37.5 & \multirow{2}{*}{0.528} \\
\hline & No & 64.7 & 68.4 & 62.5 & \\
\hline \multirow{2}{*}{$\begin{array}{l}\text { Wash your hands before } \\
\text { handling food }\end{array}$} & Yes & 97.8 & 94.0 & 98.9 & \multirow{2}{*}{0.014} \\
\hline & No & 2.2 & 6.0 & 1.1 & \\
\hline \multirow{2}{*}{$\begin{array}{l}\text { Defrost food at room } \\
\text { temperature }\end{array}$} & Yes & 89.7 & 88.0 & 85.3 & \multirow{2}{*}{0.417} \\
\hline & No & 10.3 & 12.0 & 14.7 & \\
\hline
\end{tabular}

\section{Discussion}

In the present study, attitudes and practices of hygiene and food handling were evaluated during the period of social isolation by COVID-19 in Peruvian households and a statistical correlation was established between the practices and the degree of education of the participants. In this study, all participants handled food at home. Women represented the highest percentage of the sample. Furthermore, we have found that the highest proportion of participants considered correct handling of food at home important during social isolation. Moreover, almost half of the sample began to emphasize good handling practices when the COVID-19 pandemic began. In general, the participants demonstrated a positive attitude and were aware of the role of hygienic practices when handling food. Hand washing practices were more frequent in participants with a higher level of education.

Regarding the sociodemographic data of the participants, the largest proportion of the sample was made up of women. This finding was consistent with the results of similar studies (Akabanda et al., 2017; Teffo and Tabit, 2020). This finding validates the Peruvian reality, because women, in the Peruvian context, are traditionally considered responsible for the activities of preparing food at home. Furthermore, this category of the population is more represented in food services compared to their male counterparts (Carrasco et al., 2014). On the other hand, more than half considered correct handling of food is important. The possible justification could be due, at least partially, to the fact that the majority of the participants had a higher academic degree $(53 \%, \mathrm{n}=285)$, which in turn, highlights the importance of education level in schools' positive attitudes regarding hygiene and food handling. Likewise, the reason most of the participants had a higher academic degree could be attributed to the fact that many young indigenous Peruvians and AfroPeruvians, after the second half of the 20th century, have had increasing access to higher education than the time when the university was the field of reproduction of the aristocratic privileges of education, excluding the indigenous (Mejía-Navarrete, 2018).

Almost half of the participants indicated that they had begun to emphasize good food handling practices after the COVID-19 pandemic began. This finding shows that COVID-19 has generated many concerns in the population due to speculation about the possible route of transmission of the causative agent of the pandemic, severe acute respiratory syndrome coronavirus 2 (SARSCoV-2). Evidence of the risk of transmission of COVID19 through food began to appear between the months of July and August 2020 when the presence of SARS-CoV2 was detected in frozen foods, including their packaging materials and storage environments (Ceylan et al., 2020; Rizou et al., 2020; Zuber and Brüssow, 2020). In addition, the cold chain of food also promotes contamination. Laboratory studies showed that SARS$\mathrm{CoV}-2$ is highly stable under refrigeration conditions at $4^{\circ} \mathrm{C}$, in foods such as pork skin for 14 to 21 days 
(Harbourt et al., 2020). Contaminated cold-stored food can present a systematic risk of SARS-CoV-2 transmission among the population (Han et al., 2020; Mercier et al., 2017).

Furthermore, the participants demonstrated being aware of the importance of hygienic practices when handling food at home. This affirms previous findings in which respondents changed their practices related to hygiene and food safety during the COVID-19 pandemic (Luo et al., 2020). Two possible reasons could justify these results, on the one hand, the positive attitude of our study population may play a key role in proper hygienic practices when handling food, which can help mitigate the risks of disease outbreaks transmitted by the food. In fact, there is a strong link between positive attitudes and maintaining safe food handling practices (Akabanda et al., 2017). On the other hand, since the study was carried out in a period of a health emergency, the results obtained could probably be due to the fact that the participants paid more attention and interest on the health and nutrition education topics disseminated thanks to the initiative of the media and different platforms. In fact, the attention paid to knowledge about nutrition and health is significantly associated with good practices regarding food safety (Luo et al., 2020). This situation creates for government authorities and health professionals, especially dietitians, a great opportunity to further strengthen nutrition education and healthy lifestyles for the benefit of the population at a time when people are paying more attention and interest.

The results of the study revealed that the highest proportion of the participants practised hand washing. These findings are consistent with the results reported in similar studies (Akabanda et al., 2017; Ncube et al., 2020). Studies of foodborne illness outbreaks have shown that poor personal hygiene, especially hand washing, is a major risk factor (Lambrechts et al., 2014). The main reason why it is important to ensure proper handwashing when handling food is to prevent the transmission of viruses and bacteria as they are present in the human body (Lues and Van Tonder, 2007). On the other hand, COVID-19 could arrive in fresh foods such as fruits and vegetables or in food packaging through an infected person who sneezes or coughs directly on them. The transfer appears to be possible if the virus is transferred shortly thereafter through hands or food to the mucous membranes of the mouth, throat, or eyes (Rizou et al., 2020). However, hand washing and the use of hand sanitisers represent an effective way to reduce the potential risk of touching food exposed to COVID19. Furthermore, studies suggest that normal cooking temperatures $\left(>70^{\circ} \mathrm{C}\right)$ are sufficient to inactivate COVID -19 , however, frozen foods represent a high risk of transmission; therefore, it is imperative to wash your hands properly before and after handling them (Chin et al., 2020).

In addition, the practice of handwashing was more frequent in the participants with a higher level of education. These results are congruent with evidence found in other studies (Duggan et al., 2008). The higher the level of education of the people who handle food at home, the easier it will be for them to adopt good practices regarding good food handling practices (Gaungoo and Jeewon, 2013). However, these findings are not consistent with the results observed in similar studies, in which no significant relationship was found between the level of education and hygiene practices in food handlers (Fariba et al., 2018). The degree of education does not necessarily lead to changes in food safety practices (Ansari-Lari et al., 2010).

Regarding the purchase of dairy and meat products, $63.1 \%$ of the participants indicated that these are made at the beginning or intermediate. Similar results were reported by a sample of 2,024 Chileans who handle food at home (Torres et al., 2018). This situation increases the risk of loss of the cold chain, increasing the risk of contamination. Frozen and refrigerated foods should be considered as potential vectors as part of policies and strategies to reduce the risks of food contamination and foodborne illnesses. The prevention of foodborne infections and illnesses depends to a great extent on the quality of the purchase method, the transport and the correct use and maintenance of utensils and equipment, and the appropriate hygiene techniques of preparation (Makwana et al., 2015; Jung et al., 2017).

\subsection{Limitations}

This study is the first to evaluate hygienic attitudes and practices and food handling during social isolation by COVID-19 in a relatively high number of Peruvians who handle food at home. However, this study has some limitations that must be considered. First of all, it is a cross-sectional study, so the results cannot be generalized. Second, the practices were self-reported, we did not have the opportunity to observe the hygiene and food handling practices of the participants who were selected, so an observational design study is recommended, taking observation as a collection tool. of samples.

\section{Conclusion}

In general, the participants demonstrated a positive attitude and were aware of the role of good food handling practices in the home. These results could be influenced by the health emergency that the whole world 
is experiencing, caused by COVID-19. In addition, the results of this study can be made available to government authorities and health professionals, especially dietitians, to further strengthen nutrition education, healthy lifestyles, and proper food handling for the population in a time when people are paying more attention and interest to health issues.

\section{Conflict of interest}

The authors declare no conflicts of interest.

\section{References}

Akabanda, F., Hlortsi, E.H. and Owusu-Kwarteng, J. (2017). Food safety knowledge, attitudes and practices of institutional food-handlers in Ghana. BMC Public Health, 17, 40. https://doi.org/10.1186/ s12889-016-3986-9

Ansari-Lari, M., Soodbakhsh, S. and Lakzadeh, L. (2010). Knowledge, attitudes and practices of workers on food hygienic practices in meat processing plants in Fars, Iran. Food Control, 21(3), 260-263.

https://doi.org/10.1016/

j.foodcont.2009.06.003

Carrasco, M., Guevara, B. and Falcón, N. (2014). Conocimientos y buenas prácticas de manufactura en personas dedicadas a la elaboración y expendio de alimentos preparados, en el distrito de Los Olivos, Lima-Perú. Salud Y Tecnología Veterinaria, 1(1), 7 13. https://doi.org/10.20453/stv.v1i1.104

Ceylan, Z., Meral, R. and Cetinkaya, T. (2020). Relevance of SARS-CoV-2 in food safety and food hygiene: potential preventive measures, suggestions and nanotechnological approaches. VirusDisease, 31 (2), 154-160. https://doi.org/10.1007/s13337-02000611-0

Chin, A.W.H., Chu, J.T.S., Perera, M.R.A., Hui, K.P.Y., Yen, H.L., Chan, M.C.W., Peiris, M. and Poon, L.L.M. (2020). Stability of SARS-CoV-2 in different environmental conditions. The Lancet Microbe, 1(1), e10. https://doi.org/10.1016/s2666-5247(20)30003-3

Duggan, J.M., Hensley, S., Khuder, S., Papadimos, T.J. and Jacobs, L. (2008). Inverse Correlation Between Level of Professional Education and Rate of Handwashing Compliance in a Teaching Hospital. Infection Control and Hospital Epidemiology, 29(6), 534-538. https://doi.org/10.1086/588164

Fariba, R., Gholamreza, J.K., Saharnaz, N., Ehsan, H. and Masoud, Y. (2018). Knowledge, attitude, and practice among food handlers of semi-industrial catering: a cross sectional study at one of the governmental organization in Tehran. Journal of Environmental Health Science and Engineering, 16
(2), 249-256. https://doi.org/10.1007/s40201-0180312-8

FDA. (2020). Best Practices for Retail Food Stores, Restaurants, and Food Pick-Up/Delivery Services During the COVID-19 Pandemic | FDA. Retrieved November 24, 2020, from FDA website: https:// www.fda.gov/food/food-safety-during-emergencies/ best-practices-retail-food-stores-restaurants-and-food -pick-updelivery-services-during-covid-19

Galanakis, C.M. (2020). The Food Systems in the Era of the Coronavirus (COVID-19) Pandemic Crisis. Foods, 9(4), 523. https://doi.org/10.3390/ foods 9040523

Gaungoo, Y. and Jeewon, R. (2013). Effectiveness of training among food handlers: A review on the mauritian framework. Current Research in Nutrition and Food Science, 1(1), 1-9. https:// doi.org/10.12944/CRNFSJ.1.1.01

Gobierno del Perú. (2020a). Decreto Supremo - № 0082020-SA - Poder Ejecutivo - Salud. Retrieved October 18, 2020, from GOB website: https:// www.gob.pe/institucion/minsa/normaslegales/829329-020-2020-sa. [In Spanish].

Gobierno del Perú. (2020b). Decreto Supremo - Nº 0272020-SA - Poder Ejecutivo - Salud. Retrieved October 18, 2020, from GOB website: https:// www.gob.pe/institucion/minsa/normaslegales/829329-020-2020-sa. [In Spanish].

Han, J., Zhang, X., He, S. and Jia, P. (2020). Can the coronavirus disease be transmitted from food? A review of evidence, risks, policies and knowledge gaps. Environmental Chemistry Letters, 19, 5-16. https://doi.org/10.1007/s10311-020-01101-x

Harbourt, D.E., Haddow, A.D., Piper, A.E., Bloomfield, H., Kearney, B.J., Fetterer, D., Gibson, K. and Minogue, T. (2020). Modeling the stability of severe acute respiratory syndrome coronavirus 2 (SARSCoV-2) on skin, currency, and clothing. PLOS Neglected Tropical Diseases, 14(11), e0008831. https://doi.org/10.1371/journal.pntd.0008831

Jung, J., Friedrich, L.M., Danyluk, M.D. and Schaffner, D.W. (2017). Quantification of transfer of salmonella from citrus fruits to peel, edible portion, and gloved hands during hand peeling. Journal of Food Protection, 80(6), 933-939. https:// doi.org/10.4315/0362-028X.JFP-16-423

Lambrechts, A., Human, I., Doughari, J. and Lues, J. (2014). Bacterial contamination of the hands of food handlers as indicator of hand washing efficacy in some convenient food industries in South Africa. Pakistan Journal of Medical Sciences, 30(4), 755758. http://dx.doi.org/10.12669/pjms.304.4400 
Lues, J.F.R. and Van Tonder, I. (2007). The occurrence of indicator bacteria on hands and aprons of food handlers in the delicatessen sections of a retail group. Food Control, 18(4), 326-332. https:// doi.org/10.1016/j.foodcont.2005.10.010

Luo, Y., Chen, L., Xu, F., Gao, X., Han, D. and Na, L. (2020). Investigation on knowledge, attitudes, and practices about food safety and nutrition in the Chinese during the epidemic of corona virus disease 2019. Public Health Nutrition, 24(2), 267-274. https://doi.org/10.1017/S1368980020002797

Makwana, P.P., Nayak, J.B., Brahmbhatt, M.N. and Chaudhary, J.H. (2015). Detection of Salmonella spp. from chevon, mutton and its environment in retail meat shops in Anand city (Gujarat), India. Veterinary World, 8(3), 388-392. https:// doi.org/10.14202/vetworld.2015.388-392

Mejía-Navarrete, J. (2018). El proceso de la educación superior en el Perú. La descolonialidad del saber universitario. Cinta de Moebio, 61, 56-71. https:// doi.org/10.4067/S0717-554X2018000100056 [In Spanish].

Mercier, S., Villeneuve, S., Mondor, M. and Uysal, I. (2017). Time-Temperature Management Along the Food Cold Chain: A Review of Recent Developments. Comprehensive Reviews in Food Science and Food Safety, 16(4), 647-667. https:// doi.org/10.1111/1541-4337.12269

Ministerio de Salud del Perú. (2020). Día Mundial de la Inocuidad de los Alimentos. Retrieved November 24, 2020, from http://www.digesa.minsa.gob.pe/ noticias/Junio2020/nota18.asp

Ncube, F., Kanda, A., Chijokwe, M., Mabaya, G. and Nyamugure, T. (2020). Food safety knowledge, attitudes and practices of restaurant food handlers in a lower-middle-income country. Food Science and Nutrition, 8(3), 1677-1687. https://doi.org/10.1002/ fsn 3.1454

Otzen, T. and Manterola, C. (2017). Técnicas de Muestreo sobre una Población a Estudio. International Journal of Morphology, 35(1), 227$232 . \quad$ https://doi.org/10.4067/S071795022017000100037

Phelan, A.L., Katz, R. and Gostin, L.O. (2020). The Novel Coronavirus Originating in Wuhan, China: Challenges for Global Health Governance. JAMA Journal of the American Medical Association, 323 (8), 709-710. https://doi.org/10.1001/ jama.2020.1097

Rizou, M., Galanakis, I.M., Aldawoud, T.M.S. and Galanakis, C.M. (2020). Safety of foods, food supply chain and environment within the COVID-19 pandemic. Trends in Food Science and Technology, 102, 293-299. https://doi.org/10.1016/ j.tifs. 2020.06 .008

Shi, C., Zhang, Y., Li, C., Li, P. and Zhu, H. (2020). Using the Delphi Method to Identify Risk Factors Contributing to Adverse Events in Residential Aged Care Facilities. Risk Management and Healthcare Policy, 13, 523-537. https://doi.org/10.2147/ RMHP.S243929

Teffo, L.A. and Tabit, F.T. (2020). An assessment of the food safety knowledge and attitudes of food handlers in hospitals. BMC Public Health, 20(1), 311. https:// doi.org/10.1186/s12889-020-8430-5

Tegegne, H.A. and Phyo, H.W.W. (2017). Food safety knowledge, attitude and practices of meat handler in abattoir and retail meat shops of Jigjiga Town, Ethiopia. Journal of Preventive Medicine and Hygiene, 58(4), E320. https://doi.org/10.15167/2421 -4248/JPMH2017.58.4.737

Torres, J., Voisier, A., Berríos, I., Pitto, N. and Agüero, S.D. (2018). Conocimiento y aplicación en prácticas higiénicas en la elaboración de alimentos y autoreporte de intoxicaciones alimentarias en hogares chilenos. Revista Chilena de Infectología, 35(5), 483 -489. https://doi.org/10.4067/s071610182018000500483

Velavan, T.P. and Meyer, C.G. (2020). The COVID-19 epidemic. Tropical Medicine and International Health, 25(3), 278-280. https://doi.org/10.1111/ tmi. 13383

Zuber, S. and Brüssow, H. (2020). COVID 19: challenges for virologists in the food industry. Microbial Biotechnology, 13(6), 1689-1701. https:// doi.org/10.1111/1751-7915.13638 